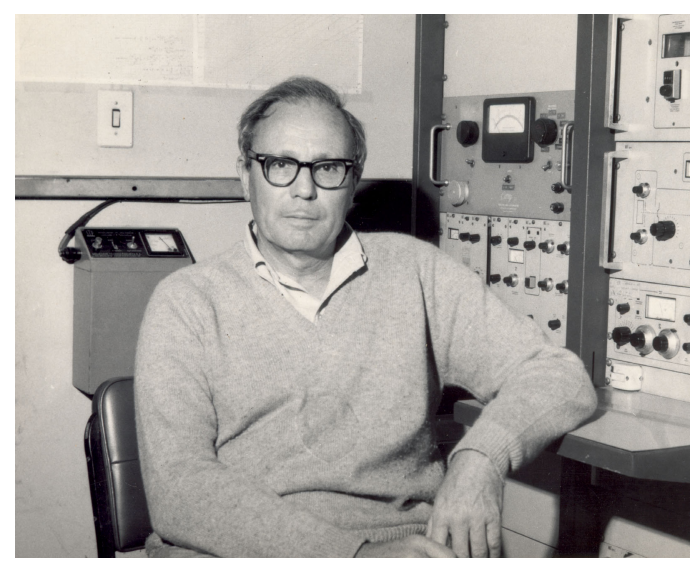

\title{
DEDICATION TO JOHN HAMILTON REYNOLDS (1923 - 2000)
}

\section{Prepared by UMBERTO CORDANI for the Third SSAGI - Pucon, Chile, 2001}

All of us, South American geochronologists, will be forever indebted to John Hamilton Reynolds. It was his idea, back in the late fifties and early sixties, to set up what was to be the first geochronology laboratory on our continent.

John was at that time a very respected senior physicist, Professor of Physics at the University of California at Berkeley. He was an expert in the field of mass spectrometry, and especially in the handling of noble gases in natural systems. His contributions to the theory of nucleosynthesis and the evolution of the early Solar System are outstanding. He had the idea of studying the extinct 
radioactivities and especially the existence of ${ }^{129} \mathrm{Xe}$ as a daughter of short half-lived ${ }^{129} \mathrm{I}$ in meteorites. This gave birth to "Xenology", a theory by which it was possible to estimate the time in which a supernova made, and immediately launched into space, the matter that eventually coalesced at some later time to form our Sun and its planets.

John was also the one that developed the instrument that, for about two decades, dominated the measurement of argon for K-Ar laboratories. The Reynolds-type pyrex-glass mass spectrometers were used by pioneers in that method, such as Garniss Curtis at the University of California at Berkeley, Brent Dalrymple in the USGS laboratory at Menlo Park, Ian McDougall at the Australian National University at Canberra and many others.

He was to make good use of a sabbatical license in 1964, and carefully planned to set up a complete K-Ar laboratory in a given place of South America, yet to be selected. He received in 1962 a NSF grant of nearly US $\$ 110,000$ (quite a large amount at that time!), purchased all equipment as well as the necessary spare parts, and went on to choose an adequate research centre in South America to collaborate and receive the laboratory. To my own good luck, he turned out to select the University of São Paulo, convinced by the positive information given by Viktor Leinz, Professor and Chief of the Department of Geology, and especially by Norman Herz, a USGS geologist acting at that time as Visiting Professor at the University. Professor Leinz asked me to take part in the collaboration, and to receive appropriate training at Berkeley. I had then the opportunity and the privilege to work at Reynolds' laboratory, during five months in 1963, and also to be received at his family home.

John and I traveled to Brazil in late 1963, together with the equipment, and the laboratory was installed in less than three months. The first K-Ar measurements of the new laboratory were obtained in January 1964. Since that time, he was our patient teacher (in addition to myself, the very first Brazilian geochronologists included Koji Kawashita and Gilberto Amaral), and taught us how to perform experimental research, from planning to interpretation; sampling procedures; and tests for precision, calibration, and overall quality of measurements. Above all, we valued his conveyance of ethics, respect, and humbleness toward Knowledge and Science. He conducted us to the search for first class measurements, and frontier research. He wanted to be co-author only on the very first two scientific articles, published in Geochimica et Cosmochimica Acta, and guided us to participate in the test of continental drift, in collaboration with MIT colleagues, when for the first time rock samples from Northeast Brazil an West Africa were dated by the K-Ar and Rb-Sr methods. This scientific effort resulted in a joint article published in Science in 1967, that was considered an important contribution in the context of the newly proposed theory of plate tectonics.

During his stay at the São Paulo laboratory, John stimulated interactions with colleagues of other Brazilian institutions, and colleagues form neighboring countries. In this respect, in 1965 we started to receive researchers from Argentina (Horacio Cazeneuve) and Chile (Fernando Munizaga), a tradition that was kept and continues up to the present. John kept track and was always ready to help us with advice, and with the remittance of spare parts of equipment. He was also very handy in helping Enrique Linares to set up INGEIS at Buenos Aires, and especially in helping Martim Portugal Ferreira to set up the K-Ar facilities at the University of Coimbra, where he had another sabbatical license in 1971.

Many of us had the opportunity to meet John during the first SSAGI, in 1997, in Campos do Jordão. That was the last time I met him, and I could witness his great satisfaction with the good level attained by geochronology in South America.

John Hamilton Reynolds passed away on November 4, 2000, after a serious pneumonia. However, his contribution to Science is lasting. Those of us who were fortunate to have been associated with him will remember John with affection and deep respect. He has been greatly missed. 